\title{
Política educacional, formação de professores e profissão docente: um olhar sobre a formação docente em história na UECE
}

Education policy, teacher training and teaching profession: a look on the training teachers in History at UECE

Política educacional, formación de profesores y profesión docente: una visión sobre la formación docente en historia en UECE

\section{Augusto Ridson de Araújo Miranda1 Antonio Germano Magalhães Junior ${ }^{2}$}

\section{Resumo}

Este artigo visa conceituar e relacionar as temáticas de "Política Educacional", "Formação de Professores" e "Profissão Docente", a partir dos estudos de Saravia (2007); Lerche (2007); Moehlecke (2012); Gatti (2010); Gauthier et al (1998); Tardif (2002); Tardif; Lessard (2011); entre outras bibliografias. Tomamos como recorte temporal as demandas conjunturais dos últimos 20 anos. Após isto tomamos como exemplo um caso único (a licenciatura em História na Universidade Estadual do Ceará) para materializar reflexões acerca destas relações. Por fim, delineamos possibilidades para repensar as políticas educacionais para Formação de Professores, com vistas a contribuir para uma profissionalização docente no Brasil.

Palavras-Chave: Política Educacional; Formação de Professores; Profissão Docente; Formação docente em História

1 Mestrando em Educação (UECE). Especialista em Metodologia do Ensino de História (UECE). E-mail: ridsonufchistoria@yahoo.com.br 2 Pós-doutor em Educação (UECE) Professor do Programa de Pós-Graduação em Educação (UECE). E-mail: germano.junior@uece.br 


\begin{abstract}
This article aims to conceptualize and relate the themes of "Education Policy", "Teacher Education" and "Teaching Profession", dialoguing with Saravia (2007); Lerche (2007); Moehlecke (2012); Gatti (2010); Gauthier et al (1998); Tardif (2002); Tardif; Lessard (2011); between another bibliographies. We take as temporal cut short-term demands of the past 20 years. After this we take the example of a single case (a degree in History at Universidade Estadual do Ceará) to materialize reflections on these relationships. Finally, we outline possibilities to rethink the educational policies for Teacher Education, in order to contribute to the professionalization in Brazil.
\end{abstract}

Keywords: Educational Policy; Teacher Education; Teaching Profession; Teacher training in History

\title{
Resumen
}

Este artículo pretende conceptualizar y relacionar las temáticas de "Política Educacional, Formación de Profesores" y "Profesión Docente", desde los estudios de Saravia (2007); Lerche (2007); Moehlecke (2012); Gatti (2010); Gauthier et al (1998); Tardif (2002); Tardif; Lessard (2011); entre otras bibliografías. Tomamos como marco de tiempo las demandas conjeturales de los últimos 20 años. Enseguida, tomamos como ejemplo un caso único (la licenciatura en Historia en la Universidad Estadual de Ceará) para materializar reflexiones sobre estas relaciones. Por fin, delinearemos posibilidades para repensar las políticas educacionales para Formación de profesores, con vistas a contribuir para una profesionalización docente en Brasil.

Palabras-clave: Política Educacional; Formación de Profesores; Profesión Docente; Formación Docente en Historia. 
Este texto tem o intuito de conceituar e relacionar as temáticas de "Política Educacional", "Formação de Professores" e "Profissão Docente", tendo como recorte temporal as demandas conjunturais dos últimos 20 anos, embora dialogaremos com os processos histórico-culturais normativos de cada tema em um sentido mais amplo. Após isto tomamos como exemplo um caso único (a licenciatura em História na Universidade Estadual do Ceará) para pensar estas relações. Por fim, delineamos uma reflexão acerca de possibilidades para repensar as políticas educacionais para Formação de Professores, com vistas a contribuir para uma profissionalização docente no Brasil.

\section{Políticas Públicas e Políticas Educacionais}

Conceituando "Política Pública", Saravia em "Introdução à Teoria da Política Pública" (2007), entende os esforços governamentais para equilibrar ou desequilibrar relações socioeconômicas, por meio de fluxos de decisões políticas. Esta noção está atrelada às tradições jurídicas tanto dos povos anglosaxões (com base em leis articuladas aos princípios dos interesses comuns dos cidadãos, dos direitos em base de costumes e da jurisprudência) como dos povos latinos, de origem romana (com base na crença no Estado, organismo objetivo de organização social dos indivíduos, aplicador de leis: ou seja, crença no legalismo). Saravia (2007), portanto, atrela decisões coletivas e públicas a necessidades socioeconômicas, e situa as atuais configurações de Políticas Públicas aos princípios de governança, estes tributários da Administração Pública: permeiam ações articuladas por planejamento, tecnologias comunicativas e mecanismos de centralização ou descentralização, dependendo de orientações técnicas e ideológicas de quem as formula e executa.

Saravia (2007), bem como Vieira e Farias em "Política(s) e Gestão da educação Básica: revisitando conceitos simples" (2007), entendem que toda política pública é feita por processos hermenêuticos de elaboração de Planos (ou planejamentos) Globais de governo; seguidos por projetos macroorganizacionais (como os de Educação); estes que permeiam programas de governo (pensados a priori como sazonais e estratégicos); que possam se desenvolver em Políticas (a longo prazo), reorientadas por programas específicos, estes contendo planos e estratégias específicos. Ao formular uma política pública, a pauta deve primeiro ser incluída na agenda governamental (ou seja, adquirir status de problema político); ser elaborada (textualmente), formulada (no processo de decisões e negociações políticas, intersubjetivas e interinstitucionais), implementada (fase de testes), propriamente executada (processo de operacionalização da política), supervisionada e, por fim, avaliada (possibilitando sua continuação, reformulação ou término), constituindo assim as etapas do processo.

Toda política pública requer atenção aos condicionantes do processo que a constitui, como o valor político empregado, as condições de implementação (prática, ou seja, a viabilidade) e as condições políticas (de aceitabilidade) impregnadas, isto quer dizer que os administradores públicos e os demais sujeitos operacionais destas políticas devem ter em vista suas contingências, entraves internos e externos, além das influências internacionais a que devem ignorar, ou dialogar, ou submeter-se. Por exemplo, de acordo com a Declaração de Jomtien, de 1990, os índices de evasão escolar nos anos 2000 dos países signatários deveriam reduzir a um número inferior a 5\%, entretanto, diversos países não puderam efetivar a meta, uma vez que as condições concretas produzidas nas relações sociohistóricas e nas tensões políticas que perpassam os valores políticos imbuídos nesta meta, que prevê ações de curto, médio e longo prazo (e alcance), são contingências que países como o Brasil sofrem. Observando os Planos Nacionais de Educação do Brasil, de vigências decenais (o de 2001 e o de 2011, apenas aprovado em 2014), a temática da evasão escolar é problemática e foco de diferentes estratégias, esforço em tese do governo brasileiro de superá-la, mas que deve lidar com esta pressão internacional e ao mesmo tempo, com os sujeitos que devem executá-la (agentes educacionais, professores, alunos, pais, comunidade, etc.).

No tocante às influências internacionais, outra temática que pode ser abordada aqui é a da predominância de valores identificados como neoliberais por diversas literaturas com as quais dialogaremos nesta escrita, 
sobretudo em "Educação Superior: tendências e estratégias de expansão na América Latina e no Brasil", de Barbalho (2011) e "Política Pública educacional e sua dimensão internacional: abordagens teóricas", de Amaral (2010); ambos tomando como fio condutor as Políticas Educacionais, situam os organismos multilaterais internacionais como propagadores de valores tais como "sociedade cognitiva mundial" (uma rede de troca de informações, entendida equivocadamente como conhecimento, em escala mundial); "globalização" (fenômeno de múltiplas formas de significação, como por exemplo: rede de trocas culturais e materiais em escala mundial); "sociedade da informação" (uma sociedade da modernidade tardia que supervaloriza a informação corrente, e que pouco exalta a profundidade de informações articuladas e problematizadas que vislumbrem a possibilidade de construção efetiva de conhecimento); a necessidade de "aprender a aprender" (meta educacional da Declaração de Jomtiem e demais produtos multiorganizacionais da UNESCO, articulada com o valor da adaptabilidade de produção de conhecimentos e saberes dos indivíduos, com base na capacidade de aprender a lógica da organização cognitiva); que por sua vez dialogam com valores como "adaptabilidade", "flexibilidade" e a aquisição de "competências e habilidades" para o mercado de trabalho (este renomeado como "mundos do trabalho", para relativizar a carga exploratória do termo "mercado").

De inspiração neoliberal (ou seja, com base no princípio dos indivíduos e de organizações de cunho empresarial, bem como as organizações estatais, de fluidificar suas relações comerciais e decisões políticas, evitando excessivas regulações e/ou intervenções estatais) ou não, os valores supracitados demarcam a flexibilização e diálogo entre fronteiras políticas e institucionais, e a descentralização das políticas públicas dos poderes estatais, em que entidades civis e empresas multinacionais promovem princípios de governança e gestão de recursos humanos. Ou seja, é a tendência apontada por Amaral (2010) de busca de fluidez e agilidade das instâncias políticas em diálogo com outras instâncias públicas e indivíduos na busca por melhor gestão dos recursos a que o Estado (e parcerias) possui.

Lerche Vieira e Farias (2007) nos ajuda a entender e a situar as Políticas Educacionais dentro do escopo das Políticas Públicas, articulando os valores de governança e gestão às diferentes dimensões educacionais. A autora distingue diferentes modalidades de gestão, como a Gestão Educacional (macro) e a Gestão Escolar, problematizando tais conceituações e pontuando que cada âmbito deva estar articulado com as legislações educacionais, bem como às Políticas Educacionais nacionais e internacionais. Neste sentido, a Gestão Educacional dialoga com as políticas educacionais na promoção de estratégias públicas que garantam os valores propostos pela Constituição Federal (no caso, a atual de 1988), a LDB (Lei de Diretrizes e Bases da Educacional) de 1996 e balizadas pelas avaliações externas, como o Exame Nacional do Ensino Médio (ENEM) e o Sistema de Avaliação da Educação Básica (SAEB). Efetivamente, esta dimensão macro deve dialogar com a dimensão micro, da Gestão Escolar, que tem como condições de implementação os documentos oficiais da escola (como o Projeto Político-Pedagógico da escola (PPP) e o regimento escolar, por exemplo), as leis locais (âmbitos estadual e municipal) e as avaliações internas da escola (elaboradas pelos professores), além das avaliações externas locais (estaduais e municipais) que porventura existam.

Lerche Vieira e Farias (2007) igualmente nos adverte para não considerarmos apenas o enfoque nas legislações e dispositivos documentais. Neste sentido, devemos ir além e buscar compreender os ditames intersubjetivos (nas apropriações de sujeitos e instituições às legislações, suas compreensões pessoais e visões de mundo), as condições de exequibilidade e/ou desarticulação das políticas educacionais. Pacheco (2006) neste sentido, também nos adverte para compreendermos as Políticas Educacionais na condição de formulações curriculares, que requerem a atenção dos pesquisadores em Educação para diferenciar as condições concretas das práticas dos sujeitos educacionais com as propostas prescritas nos documentos oficiais.

O distanciamento entre os dispositivos legais e as efetivas práticas é temática discutida por diversos autores, como Barbalho (2011), já supracitada; também Sabrina Moehlecke (2012) em "O ensino médio e as novas diretrizes curriculares nacionais: entre recorrências e novas inquietações"; e Bernadete Gatti (2010), em 
"Formação de Professores no Brasil: características e problemas" e em "Políticas Docentes no nível federal: a perspectiva de um Sistema Nacional de Educação" (GATTI et al, 2011). Respectivamente as autoras abordam as dificuldades de execução das políticas educacionais com a qualidade do ensino superior público na América Latina e Brasil; no Ensino Médio brasileiro; nos cursos de licenciatura em Pedagogia, Letras (em suas diversas habilitações), Matemática e Biologia; e nos cursos em Educação à Distância (EaD), e apontam para a ineficácia dos Planos Nacionais de Educação (nas versões de 2001 e 2011) e suas metas, bem como nas diferentes modalidades de Diretrizes Curriculares Nacionais (DCNs), como as de Formação de Professores, e do Ensino Médio, em induzir mudanças significativas na qualidade da educação brasileira em contrapartida às relações socioculturais construídas historicamente e entendidas apenas em um recorte temporal de longa duração.

Ora vagos, ora pouco exequíveis, os documentos legais esbarram por exemplo nas ações dos sujeitos, tanto por não conhecerem o conteúdo, ou as intencionalidades, ou por conhecerem e discordarem de suas pretensões. Dois bons exemplos disso são a "Política Nacionais de Formação de Professores" e as "DCNs de Formação de Professores para a Educação Básica". O primeiro exemplo, segundo Gatti et al (2011), por prioritariamente se embasarem na EaD, sofre com as condições estruturais e socioeconômicas de professores licenciados, de licenciandos e de bacharéis que atuam na licenciatura, pelo não acesso à internet ou a dificuldade de deslocamento de suas casas para os pólos de acesso digital; o segundo exemplo, segundo Gatti (2010), são sumariamente ignoradas nos PPPs de diversos cursos de licenciatura apontados em todo o país, que se delineiam bacharelados em suas configurações curriculares.

Pelos exemplos supracitados, podemos destacar que uma parcela significativa das Políticas Educacionais perpassa preocupações com as condições profissionais dos professores e as Formações Docentes; de outra forma, conforme indicado por Lerche Vieira e Farias (2007), os professores, situados estrategicamente nas dinâmicas educacionais como um dos principais (mas não os únicos) atores escolares, redimensionando as estratégias de tais políticas no cotidiano de trabalho (e em seus processos formativos), favorecendo ou dificultando a exequibilidade das metas previstas pelos documentos oficiais dos diferentes âmbitos: federal; estaduais; e municipais. Entendendo isto, se faz necessário problematizar os conceitos de "Formação de Professores" e "Profissão docente" para melhor delinear estas categorias com as Políticas Educacionais, afim de vislumbrar possibilidades mais exequíveis para estas.

\section{Formação de Professores: caminhos necessários para a profissão docente}

Imbernón, em "Formação docente e profissional: formar-se para a mudança e a incerteza", discute e conceitua "Formação Docente" como o processo de desenvolvimento cognitivo e social do docente, em vistas a adquirir condições de exercer sua profissão. Semelhante é o caminho conceitual apontado por Gauthier e seus colaboradores em "Por uma teoria da Pedagogia" (1998) e Tardif em "Saberes Docentes e Formação Profissional"(2002), além de Tardif \& Lessard em "O Trabalho Docente" (2011). Estas três obras indicam que a formação docente é a aquisição de saberes próprios à execução de seu trabalho, desde que mobilizados em sua prática e apontados pelos docentes como seus. Não se trata de mera aquisição de conhecimentos, mas a execução destes situados nos contextos de interação com outros indivíduos (outros professores, estudantes, pais, demais agentes escolares e outras categorias profissionais). Entendemos, com base nestas referências, que a formação de professores perpassa a vida profissional docente, desde suas escolhas prévias à formação inicial (universitária ou não), suas vivências cotidianas dentro e fora do espaço de trabalho, mas sobretudo na atuação profissional.

Há de se distinguir as diferentes modalidades de formação docente; chamaremos de Pré-Inicial (ou Escolar) as anteriores experiências antes da Formação Universitária (Inicial). Nela, o futuro docente adquire os saberes da tradição escolar, em que ele compreende o processo cultural escolar e a dinâmica organizacional da 
escola, além de coletar referências que o inclinam para a escolha para a profissão docente. Neste sentido, Gatti (2010) e Tardif (2002) apontam que decisivamente o futuro docente entra na profissão, ou por modelos de outras práticas, ou pelas condições materiais dos pais, ou por influências culturais, além de observação prática: é um emprego relativamente de vasta quantidade de vagas. Contudo, há de se resguardar o fato de que nem sempre a formação pré-inicial apresente ao futuro docente boas referências que o influenciem para uma escolha totalmente voluntária; neste sentido, Tardif \& Lessard (2011), bem como Gatti (2010) elencam variáveis para a escolha profissional, como até a falta de outras opções ou até a escolha pela licenciatura mas com a intencionalidade de prática profissional bacharelesca. Estes estudos apontam que, os futuros docentes, estatisticamente, em geral advém de escolas públicas e de rendas familiares modestas.

Na Formação Inicial, os docentes adquirem saberes epistêmicos, ligados à disciplina que lecionarão; às tradições escolares; aos relativos às Ciências Educacionais (Psicologia; Filosofia; Sociologia e História- de maneira rasa e voltada à Educação); saberes pedagógicos; e uma superficial formação nos "saberes da ação pedagógica": aquilo que Gauthier et al (1998) denominam como práticas de ensino, sociabilizadas e validadas pela comunidade acadêmica, de ações docentes nos espaços escolares que articulem conhecimentos disciplinares das ciências que ministram com princípios pedagógicos coerentes, ou seja, o que os pesquisadores acerca dos saberes docentes compreendem como "práticas de ensino bem-sucedidas" do ponto de vista da aprendizagem dos estudantes. Neste sentido, Gatti (2010) denuncia em seu estudo, como dissemos anteriormente, a superficialidade da Formação Inicial nas licenciaturas, sobretudo no que tange aos saberes ditos pedagógicos e de práticas de ensino. O que nos Estágios deveria inserir o licenciando na efetiva prática de ensino só é devidamente realizado na atuação docente fora da Formação Inicial, em que de fato o professor adquire os Saberes Experienciais (o que denominaremos de Formação Contínua).

Veiga (2005) diferencia Formação Contínua (sendo em serviço ou atrelada à prática experiencial docente no cotidiano de sua profissão) e Continuada (nos estudos pós-graduados), o que nos ajuda a dimensionar em que ponto os saberes docentes são adquiridos após a Formação Inicial, o poder do trabalho docente na formação, e em que ponto as Políticas Educacionais incidem, de diversas formas, nos processos formativos profissionais dos professores. Entendemos como Gatti (2010) e Tardif \& Lessard (2011), que é na formação docente que se adquire profissionalidade, ou seja, as condições de exercer sua profissão. Se entendemos que Profissão Docente é o estabelecimento de rotinizações burocráticas atreladas às dimensões legais, culturais e sociais, e que o professor ressignifica estas rotinas, inerente ao espaço de trabalho (escola, universidade, equipamentos culturais; demais instituições de ensino) em um processo interpretativo para lidar com as diferentes interações intersubjetivas que já apontamos anteriormente, podemos concluir que as Políticas Educacionais devem vislumbrar tanto o processo formativo docente quanto as características, e por conseguinte, os desafios atrelados à profissão docente.

\section{Caminhos entrelaçados: Políticas Educacionais, Formação de Professores e Profissão Docente:}

Como apontamos nas literaturas com que dialogamos anteriormente, as documentações legais, bem como as políticas educacionais (dos quais os documentos são reguladores e regulados), tem como uma das suas principais dimensões as diferentes etapas da Formação de Professores. O Plano Nacional de Educação (PNE) de 2014, por exemplo, tem metas de valorização dos profissionais da educação (metas 15 a 18) e metas de expansão da rede de ensino superior (12 a 14), bem como metas de expansão das modalidades de Formação Continuada (de forma direta, como de 12 a 16; e indireta nas estratégias de 17 e 18) para dar cabo às demais metas do PNE. Como se vê, tais metas interferem, mesmo que em discurso, com as condições profissionais docentes. Entretanto, as demais metas, voltadas às condições das escolas e da expansão (ou massificação, conforme Barbalho (2011) e Gatti et al (2012) indicam) da escolarização e do número de matrículas, interferem decisivamente nos conteúdos de 
Formação de Professores (não só na Contínua, mas na Continuada e até na Inicial) e nas condições profissionais docentes de formas efetivas. Gatti (2010), com base em Tardif \& Lessard (2011) entende que a profissionalidade docente é significativamente modificada com as estratégias explícitas e implícitas das políticas públicas em Educação, que contribuem decisivamente para uma progressiva destituição da profissionalização docente, uma vez que este perde o controle dos mecanismos reguladores de sua prática profissional em detrimento de objetivos massificadores da educação que põem em xeque a qualidade do trabalho docente.

Outra maneira de se perceber a intrínseca relação entre as Políticas Educacionais, Formação e Profissão docentes é percebida nos programas de inovação do Ensino Médio, com as DCNs para o Ensino Médio, de 1998 e 2011, e os demais programas compostos nas políticas educacionais para este nível, em que ao promover estratégias que visem à integração entre os objetivos propedêutico (iniciação científica e preparação para a Universidade) e profissionalizante, reverberam sensivelmente nas condições profissionais docentes, que precisam ser balizadas por formações docentes (todos os momentos e possibilidades) mais consistentes. Neste sentido Moehlecke (2012) afirma que, pelo teor não-diretivo das DCNs para o Ensino Médio, as políticas educacionais para este nível ficam comprometidas, na medida em que abrem excessivas possibilidades para sua execução e que abrem brecha a interpretações de toda espécie, em que muitas delas levam ao conformismo e deformação das proposições. Neste caso, as formações docentes que dialogam com este nível de ensino devem perceber que cada segmento destas DCNs incide nas condições profissionais: isto é, devem ser conhecidas, discutidas e problematizadas por estas etapas formativas.

Além dos exemplos elencados anteriormente, devemos entender, em uma perspectiva contextual, as reverberações das relações entre as Políticas Educacionais e os docentes (seus percursos formativos e sua profissão). Com a "sociedade da informação" atual, configurada em moldes globalizados (conforme apontado por Bauman em "Sobre Educação e Juventude" (2013)) e nas crises das relações com o saber, apontados por Charlot (2013) como efeitos colaterais das crises de legitimidade da escola, dos professores e da necessidade de aprender os conteúdos escolares, que por sua vez (conforme Bauman e Charlot igualmente apontam) são efeitos colaterais das ondas neoliberais e da modernidade tardia (o que Hall (2005) denomina de pósmodernidade), as Políticas Educacionais no Brasil são reféns das pressões internacionais por massificação das redes escolares e do Ensino Superior, que encontram na EaD uma possibilidade de caminho mais rápida e sustentável. Entretanto, como Gatti et al (2011) apontam, entre a massificação e a qualidade da EaD, há um abismo a ser superado, decorrente das geralmente (mas não iremos ser deterministas) superficiais formações docentes à distância. Isto não quer dizer, em contrapartida, que não se permita reconhecer a importância da sociedade de informação e da massificação de possibilidades formativas, nem do alcance que estas possuem na redução (ainda que tímida) das desigualdades sociais.

\section{Um caso para se pensar: as Políticas Educacionais que incidem na Formação docente em História na UECE}

Diversas são as modalidades de Políticas Educacionais que possam incidir em um curso de Formação de professores, como já referenciado anteriormente. Contudo, para materializar de maneira mais concreta nossa análise, escolhemos um caso específico, por se tratar de nosso objeto de pesquisas no núcleo de estudos em História e Avaliação Educacional no Programa de Pós-Graduação em Educação na UECE, e de nossa realidade local, o curso de licenciatura em História da UECE.

Além de outras documentações possíveis, inclusive as já citadas Lei n 9394/96 (Lei de Diretrizes e Bases da Educação brasileira em vigor) e os PNE posteriores a esta lei organizacional, concretamente as Políticas Educacionais dialogam com os cursos de licenciatura atualmente por meio das Diretrizes Curriculares Nacionais; neste sentido, o curso de História da UECE (tomaremos como locus o de Fortaleza, por ser o mais 
antigo e o de maior demanda de formação de professores de História da referida universidade), por meio de seu Projeto Político-Pedagógico (usaremos como exemplo o de 2006, em vigor atualmente), dialoga com as Diretrizes Curriculares Nacionais para os cursos de História (2002), por meio do Parecer CNE/CES 492/2001 (que contextualiza e apresenta as DCNs dos cursos de História em linhas gerais), bem como da Resolução CNE/ CES 13, de 13 de março de 2002 (que dá as diretrizes para a composição dos PPPs dos cursos de História de licenciatura e de bacharelado); e as diferentes publicações acerca das Diretrizes Curriculares Nacionais para os cursos de Formação de Professores para a Educação Básica, em que partiremos do Parecer CNE/CP n 9 , de 8 de maio de 2001 (que estabelece as diretrizes para os cursos de formação de professores e as Resoluções CNE/ $\mathrm{CP} \mathrm{n}^{\circ} 1$ e $\mathrm{n}^{\circ} 2$, de 18 de fevereiro de 2002 (respectivamente a resolução que ratifica as diretrizes; e que ratifica a duração dos cursos e compartimentaliza a duração de cada área curricular por meio das cargas horárias). Não é intenção nossa nesta escrita delongar análises aprofundadas acerca de cada documentação, mas apenas realizar um exercício comparativo no sentido de exemplificar como estas intenções políticas prescritas nas DCNs dialogam com um caso concreto de formação de professores. Algumas conclusões podem ser extraídas deste exercício comparativo.

A primeira: O PPP do curso de licenciatura em História da UECE realiza um claro esforço no sentido de dialogar com as DCNs dos cursos de História; ao promover um percurso formativo amplo, que articulasse formação pedagógica e formação para a pesquisa historiográfica, atualizada com as demandas formativas dos historiadores que possam trabalhar não só com a licenciatura, mas com a preservação e composição de acervos arquivísticos, museológicos e demais linguagens patrimoniais, bem como produção bibliográfica e consultoria em temáticas históricas, o curso de licenciatura em História da UECE forma (em teoria) historiadores minimamente capacitados para atuar nas diferentes dimensões historiográfica. Neste sentido, ressaltamos na Justificativa deste curso (UECE, 2006, p.8) referências diretas a esta documentação, sobretudo no sentido de se articular com as "[...] novas linguagens e fontes historiográficas concebidas na renovação historiográfica que a ciência histórica perpassou no século XX [...]". Partindo da leitura de Gauthier et al (1998),em tese, a formação para adquirir os saberes disciplinares é coerente.

Segunda: há uma leve discrepância entre as DCNs dos cursos de História e o PPP da História da UECE, no sentido de uma formação em História regional, e no sentido de uma formação para a atuação em acervos. Há uma pequena proporção de disciplinas voltadas para a investigação historiográfica acerca do estado do Ceará; não existe diretamente nenhuma disciplina voltada para a organização e conservação de acervos de maneira explícita. Contudo, isto reflete o caráter mais sugestivo do que prescritivo das diretrizes curriculares em suas formulações pós-LDB de 1996, conforme apontado por Moehlecke (2012). Em fato, há um paradoxo em relação a este aspecto das DCNs: são sugestivas e dão autonomia às unidades educacionais para adaptar os PPPs às realidade locais; e ao mesmo tempo, fragilizam a execução das estratégias políticas previstas nos documentos.

Terceira: de outra forma, os cursos de licenciatura, caso como este aqui analisado, devem em larga medida não só apontar o diálogo com as DCNs específicas, mas também com as de Formação de Professores. De certa forma, o PPP do curso de História da UECE o faz. Anuncia desde as primeiras páginas este diálogo, mas de fato, na análise da proposta formativa, fica evidente que apenas dialoga com a Resolução n 2 do CNE/CP de 18 de fevereiro de 2002, em que dimensiona a duração do curso e a carga horária mínima em cada componente curricular. Contudo, nas ementas das disciplinas, fica evidente que há uma disparidade entre as disciplinas de cunho pedagógico e cunho formativo para pesquisa e formação historiográfica, revelando que a proposta formativa do curso mais se assemelha a um bacharelado. Tal perfil é analisado por Gatti (2010), no sentido de que os curso de licenciatura apartam formação didático-pedagógica e formação "conteudista". As DCNs para os cursos de Formação de Professores são claras em reconhecer estas práticas e criticá-las, indicando que os cursos devam articular estas duas dimensões, perpassando a preparação para a profissão docente em todas as disciplinas do curso. 
A análise destes documentos é reveladora das dificuldades em se propor políticas nacionais em formação de professores, pois diferentes documentações referenciais podem indicar possibilidades de apropriação dos sujeitos acerca dos programas, metas e estratégias inseridas nas variadas modalidades de Políticas Educacionais. Quando se fala em Formação de Professores, no entanto, isto se torna preocupante, na medida em que tais apropriações podem repercutir na manutenção de práticas às quais as políticas intencionam mudar. Aparentemente, nas propostas prescritas de formação dos historiadores na UECE que atuarão como professores de História, indica-se uma formação pedagógica incipiente para a prática docente, legando a estes profissionais a aquisição de saberes pedagógicos e da ação pedagógica mais nas escolas do que propriamente no espaço de formação inicial.

\section{Considerações Finais: possibilidades para melhor articular Políticas Educacionais e Formação de Professores}

Pelo que discutimos anteriormente, há uma estreita relação entre "Políticas Educacionais", "Formação de Professores" e "Profissão Docente", e que no Brasil, nos últimos 20 anos, tais relações são condicionadas por valores ditos neoliberais (mas que podem ser ressignificados em termos de governança e qualidade educacional crítico-emancipatória, conforme Moehlecke (2012) sugere, relações internacionais de políticas educacionais (materializadas em programas de avaliação como o PISA ${ }^{3}$ ) e interações multipolarizadas entre legislações, intenções públicas, sujeitos educacionais e instituições, que ressignificam-nas. Isto quer dizer que pensar Políticas Educacionais (também) é pensar os professores e suas condições de desenvolvimento profissional, que perpassam tantos os processos formativos quanto as práticas docentes. Gatti (2010) e Gatti et al (2011) mostraram que já é feito, neste sentido, um esforço de melhorias deste cenário, como por exemplo, o Plano Nacional de Formação de Professores na Educação Básica (PARFOR), inserido na Política Nacional de Formação Docente.

Entendemos, no entanto, que tais políticas educacionais devem igualmente prever e em larga medida, proporcionar, para além das Formações Contínua e Continuada, melhorias estruturais nas escolas (como por exemplo, o Programa Ensino Médio Inovador - PROEMI) e melhoria, sobretudo, na qualidade da Formação Inicial. Isto requer melhor articulação, por exemplo, entre as instâncias governamentais e os sujeitos envolvidos, mas igualmente pressões legais para articulação entre os cursos de licenciatura e as Diretrizes Curriculares Nacionais que regem estes cursos (incluindo, sobretudo a de Formação de Professores).

Pelo que foi observado na análise dos documentos legais do curso de licenciatura em História da UECE, há uma leve discrepância entre o que é pensado nas Políticas Educacionais para os cursos de História, materializada nas DCNs dos cursos de História, e o PPP do curso de História da UECE, o que em larga medida coaduna com a proposta nacional de autonomia dos cursos de História para se adequar aos anseios de produção local; contudo, há um distanciamento entre o PPP do curso de História da UECE e as DCNs dos cursos de Formação de Professores, o que incide em secundarização da missão de formação docente neste curso em detrimento à proposta formativa de pesquisadores em História, mesmo se configurando como licenciatura, e revela o que Gatti (2010) concluiu a respeito da formação docente no Brasil: uma frágil força política das políticas educacionais em valorização da formação docente inicial.

Assim, ao nos depararmos com tal cenário, e considerando as reflexões de Ferreira \& Magalhães Junior (2013), uma forma de remodelamento das Políticas Educacionais para a Formação de Professores deve ser partindo das necessidades formativas dos licenciandos e daqueles que já estão em prática profissional e atrelá-las às Formações Continuadas, tanto para vislumbrar no futuro próximo propostas curriculares mais adequadas e flexíveis, como para 
melhor preparar os futuros formadores de professores para estas necessidades nas licenciaturas. Entendemos neste aspecto uma possibilidade de melhor compor as Formações Iniciais para contribuir na profissionalização docente, e assim torná-la mais preparada para lidar com as dinâmicas de sua condição profissional.

Outra possibilidade a ser aventada aqui é a de maior incidência na Formação Inicial e nas Formações Contínua e Continuada de momentos de leitura, discussão e amadurecimento profissional acerca das Políticas Educacionais; é entendido que este momento se faz necessário para munir os professores de ferramentas que vislumbrem melhor profissionalidade, na medida em que contribuindo para sua profissionalização, isto é, de força política da categoria docente, os professores devam se acercar dos dispositivos legais e das propostas de gestão educacional. Tanto Gatti (2010) quanto Tardif \& Lessard (2011) mencionam esta possibilidade como válida. Desta forma, pensar as Políticas Educacionais se torna uma poderosa ferramenta de formação docente e de construção de uma melhor profissionalidade, uma vez que aproxima o professor das intenções políticas e, ao mesmo tempo, o transforma em sujeito remodelador de sua condição profissional.

\section{Referências}

AMARAL, M. P. Política pública educacional e sua dimensão internacional: abordagens teóricas. Educação e Pesquisa, São Paulo, v. 36, p. 39- 54, 2010.

BARBALHO, M. G. C. Tendências e Estratégias Políticas para Educação Superior na América Latina e no Brasil. In: CABRAL NETO, A. et al. (orgs.) Pontos e contrapontos da Política Educacional: uma leitura contextualizada de iniciativas governamentais. Brasília: Liberlivro, 2011

BRASIL. Parecer CNE/CES n. 492/2001 - Diretrizes Curriculares Nacionais dos cursos de História- MEC. . Parecer CNE/CP $n^{\circ}$. 28/2001 - Diretrizes Curriculares Nacionais dos cursos de História- MEC. Parecer CNE/CP $n^{\circ}$ 9, de 8 de maio de 2001. Diretrizes Curriculares Nacionais para a Formação de Professores da Educação Básica, em nível superior, curso de licenciatura, de graduação plena.

Resolução CNE/CP n 1, de 18 de fevereiro de 2002. Institui Diretrizes Curriculares Nacionais para a Formação de Professores da Educação Básica, em nível superior, curso de licenciatura, de graduação plena.

Resolução CP/CNE n², de 18 de fevereiro de 2002. Institui a duração e a carga horária dos cursos de licenciatura, de graduação plena, de formação de professores da Educação Básica em nível superior.

Lei No10.172, de 9 de janeiro de 2001. Plano Nacional de Educação (2001-2010).

Lei $N^{\circ}$ 13.005, de 25 de junho de 2014. Plano Nacional de Educação (2014-2024).

Conselho Nacional de Educação (CNE). Resolução n. 3, de 26 de junho de 1998. Institui as Diretrizes Curriculares Nacionais para o Ensino Médio. Diário Oficial da República Federativa do Brasil, Brasília, DF, 5 ago. 1998a.

Conselho Nacional de Educação (CNE). Parecer n. 15, de 1 de junho de 1998. Diretrizes Curriculares Nacionais para o Ensino Médio. Brasília, DF, 1998b.

. Conselho Nacional de Educação (CNE). Resolução $n^{\circ}$ 2, de 30 de janeiro 2012. Diretrizes Curriculares Nacionais para o Ensino Médio.

FERREIRA, Maria Nahir Batista; MAGALHÃES JUNIOR, Antônio Germano. As necessidades formativas dos professores de história. Anais do XXVII Simpósio Nacional da ANPUH, Natal, 2013

GATTI, B. A. Formação de professores no Brasil: características e problemas. Educação e Sociedade, Campinas , v. 31, n. 113, Dec. 2010 . Disponível em<http://www.scielo.br/scielo.php?script=sci_arttext\&pid=S01013302010000400016\&lng=en\&nrm=iso>. http://dx.doi.org/10.1590/S0101-73302010000400016.

BARRETTO, E. S. S; ANDRÉ, M. E. D. A. Políticas Docentes no nível federal: a perspectiva de um Sistema Nacional de Educação In: Políticas docentes no Brasil: um estado da arte . BARRETTO, E. S. S.; ANDRÉ, M. E. D. A. (orgs.) - Brasília: UNESCO, 2011. 
GAUTHIER, C. (et. al). Por uma teoria da pedagogia: pesquisas contemporâneas sobre o saber docente. ljui: Ed.UNIJUÍ, 1998.

HALL, S. A identidade cultura na pós-modernidade. 10. ed. Rio de Janeiro: P\&A, 2005

IMBERNÓN, F. Formação docente e profissional: formar-se para a mudança e a incerteza. Trad. Silvana Cobucci Leite. 9ed. São Paulo: Cortez, 2011.

MOEHLECKE, S. O ensino médio e as novas diretrizes curriculares nacionais: entre recorrências e novas inquietações. Revista Brasileira de Educação, Rio de Janeiro , v. 17, n. 49, Apr. 2012 . Disponível em <http:// www.scielo.br/scielo.php?script=sci_arttext\&pid=S1413-24782012000100003\&lng=en\&nrm=iso>. http://dx.doi. org/10.1590/S1413-24782012000100003.

PACHECO, J. A. O que se entende por currículo: In: Escritos Curriculares. São Paulo: Cortez Editora, 2006.

SARAVIA, E. Introdução à teoria da política pública. In: SARAVIA, E.; FERRAREZI, E. (Org.) Políticas públicas: coletânea. Brasília: ENAP, 2007 Vol. 1, p. 21-43.

TARDIF, M. Saberes docentes e formação profissional. Petrópolis: Vozes, 2002.

; LESSARD, C. O trabalho docente: elementos para uma teoria da docência como profissão de interações humanas. $6^{\text {a }}$ Ed. Rio de Janeiro: Vozes, 2011.

UNESCO/UNICEF. Declaração Mundial sobre Educação para Todos (Conferência de Jomtien) Jomtien, 1990. UNIVERSIDADE ESTADUAL DO CEARÁ. Projeto Pedagógico: Curso de História. Fortaleza, 2006. 30 p.

VEIGA, I. P. A. Docência universitária na educação superior. 2005. Disponível em http://porteiras.r.unipampa. edu.br/portais/cap/files/2010/10/docencia_universitaria_na_educacao_superior.pdf. Acesso em: 20/03/2015.

VIEIRA, S. L.; FARIAS, I. M. S. Política Educacional no Brasil: Introdução Histórica. Brasília: Liber Livro, 2007.

Recebido em 01/05/2015 | Aprovado em 27/06/2016 